\title{
EXPERIÊNCIAS FORMATIVAS CIBERCULTURAIS NA EDUCAÇÃO BÁSICA A PARTIR DO MOBILE GAME
}

\author{
CYBERCULTURAL TRAINING EXPERIENCES IN BASIC EDUCATION FROM MOBILE GAME \\ EXPERIENCIAS DE ENTRENAMIENTO CIBERNÉTICO EN EDUCACIÓN BÁSICA DE JUEGOS \\ MÓVILES
}

\author{
Rosemary dos Santos \\ Doutora em educação e professora adjunta da Universidade do Estado do Rio de Janeiro. \\ E-mail: rose.brisaerc@gmail.com. \\ Orcid: https://orcid.org/0000-0003-0479-1703
}

\begin{abstract}
Liliene Lopes Russell Maturana
Mestre em educação e programa de pós-graduação em educação, cultura e comunicação pela Universidade do Estado do Rio de Janeiro - UERJ / Faculdade de Educação da Baixada Fluminense - FEBF.

E-mail:304minecraft@gmail.com.

Orcid: https://orcid.org/0000-0003-4318-7875
\end{abstract}

\begin{abstract}
RESUMO
Este artigo apresenta um recorte da dissertação de mestrado intitulada Mobile game na educação básica: experiências docentes e discentes de ciberpesquisa- formação multirreferencial. Nesse sentido, trabalhamos na perspectiva da ciberpesquisa- formação multirreferencial em Ardoino (1998), Macedo, (2010) e Santos, E. (2014) Os pressupostos da investigação dialogam com pesquisas com o cotidiano de Certeau (2012) e Alves (2008), apoiados em dois dispositivos: o mobile game Minecraft Pocket Edition e dois diários de campo online. Esses diários nos permitiram chegar aos seguintes achados: percebemos que o uso do game, além das habilidades cognitivas e acadêmicas, também favorece a competição e a criatividade nas relações sociais entre jogadores, por meio de processos interativos, dialógicos, colaborativos e autorais. Apresentamos a realização de projetos em sala de aula organizados através do livro virtual Aventura Quadrada onde os conhecimentos emergentes dessa investigação apontaram para as potencialidades do Minecraft na criação de atos de currículos.
\end{abstract}

Palavras-chave: Mobile game Minecraft. Educação básica. Ciberpesquisa-Formação Multirreferencial. Atos de currículos.

\section{ABSTRACT}

This article presents an excerpt from the master's thesis entitled Mobile game in basic education: teaching experiences and students of cybersearch- multi-referential training. In this sense, we work from the perspective of cyberresearch- multi-referential training in Ardoino (1998), Macedo, (2010) and Santos, E. (2014). We dialogue with the research assumptions with the quotidian of Certeau (2012) and Alves, N. (2008), supported by two devices: the mobile game Minecraft Pocket Edition and two online field diaries. This diaries allowed us to reach the following findings: we realized that the use of the game, in addition to cognitive and academic skills, also favors competition and creativity, as well as the social relationships between players, through interactive, dialogical, collaborative, and authoring processes. We present the realization of projects in the classroom organized through the virtual book Square Adventure where the knowledge emerging from the experience in this research pointed to the potential of Minecraft in the creation of curriculum acts. 
Keywords: Mobile game Minecraft. Basic education. Cyber Research - Multireferential Training. Curriculum acts.

\section{RESUMEN}

Este artículo presenta un extracto de la tesis de maestría titulada Mobile game en educación básica: experiencias de docentes y estudiantes de ciberinvestigación - formación multirreferencial. En este sentido, trabajamos la ciberinvestigación-formación multirreferencial desde la perspectiva de Ardoino (1998), Macedo, (2010) y Santos, E. (2014). Los supuestos de la investigación dialogan con lo cotidiano de Certeau (2012) y Alves (2008), con el apoyo de dos dispositivos: el mobile game Minecraft Pocket Edition y dos diarios de campo en línea. Esos diarios nos permitieron llegar a los siguientes descubrimientos: nos dimos cuenta de que el uso del referido juego, además de las habilidades cognitivas y académicas, también favorece la competitividad y la creatividad en las relaciones sociales entre jugadores, a través de procesos interactivos, dialógicos, colaborativos y en las producciones como autores. Presentamos la realización de proyectos en el aula organizados por medio del libro virtual Square Adventure; el conocimiento que surgió de la experiencia en esta investigación señaló el potencial de Minecraft en la creación de actos curriculares.

Palabras-clave: Mobile game Minecraft. Educación básica. Ciberinvestigación-Formación multirreferencial. Actos curriculares.

\section{INTRODUÇÃO}

As discussões contemporâneas nos mostram que a partir das interações estabelecidas entre os artefatos tecnológicos móveis (smartphones) e os aplicativos (softwares), através da Internet, faz inaugurar um novo tempo para a sociedade. Um tempo diferente de todas as eras que o antecederam, conhecido por cibercultura. Como cultura da contemporaneidade e do ciberespaço mediado pelas tecnologias digitais, a cibercultura, compreendida não como outra cultura, mas, como própria dos sujeitos, segue, por sua vez, consolidando-se de maneira cada vez mais intensa, ao transformar as relações entre o ser humano e o seu contexto sócio-político-econômico-cultural, fazendo emergir outros sentidos e significações.

Essa emersão, por sua vez, nos incita outras demandas formativas e interativas. A frequente capacidade transformadora dos artefatos tecnológicos pode ser compreendida como resposta à própria demanda da sociedade. As inventividades tecnológicas, a princípio, surgiram como proposta para promover uma melhor qualidade de vida. Todavia, para além de sua simples utilidade, ao compreendemos o contexto das relações entre os artefatos tecnológicos e os sujeitos, percebemos de que não se trata de uma utilização com um fim em si mesma. O fato é que o cotidiano que se faz presente possui o poder interativo - através de diferentes acessos à internet. Ao compartilharem essas informações, potencializam um diálogo em rede jamais visto na história. Um sujeito, 
atualmente, ao sair com os seus amigos, pode ter suas ações fotografadas, filmadas, compartilhadas e seguidas com a “\# hashtag"- palavras-chave associadas a uma informação, podendo ser visualizado e comentado por milhares de outras pessoas em suas redes sociais.

Dessa maneira, temos presenciado um constante emergir dos diferentes artefatos tecnológicos criados pela sociedade contemporânea. Artefatos que nos fazem perceber decisivamente sobre novos olhares sobre o mundo. Olhares que, por sua vez, nos revelam a análise de que ao pretender pesquisar sobre os aplicativos na contemporaneidade, devese contextualizá-los para uma maior compreensão dessas implicações em seus modos de ser, sentir, perceber, significar e ressignificar a contemporaneidade. O aumento dos artefatos tecnológicos agregado à cotidianidade favorece a criação de novos cenários e novas relações. Nesse aspecto, os mobiles games surgem como frequentes mobilizadores de downloads (recebimentos de dados) e atendem a um número cada vez maior de usuários no ciberespaço.

Nesse sentido, apresentamos neste artigo um recorte da nossa pesquisa de mestrado em educação, através do Programa de Pós-graduação em Educação, Cultura e Comunicação, intitulada por “Mobile game na Educação Básica - Experiências Docentes e Discentes de "Ciberpesquisa" Formação multirreferencial”, realizada na Faculdade de Educação da Baixada Fluminense - FEBF, pertencente à Universidade do Estado do Rio de Janeiro - UERJ. O estudo traz algumas experiências e reflexões sob o olhar investigativo e curioso, político e implicado, para analisar os usos do aplicativo mobile game Minecraft como experiência curricular formativa. Os sujeitos da pesquisa foram vinte praticantes ${ }^{2}$ na faixa etária entre 8 a 14 anos de idade que cursavam o terceiro ano do ciclo ${ }^{3}$ da alfabetização no Ensino Fundamental no ano letivo de 2017. O campo investigativo foi uma escola da Rede Municipal de Educação da cidade de Duque de Caxias no Estado do Rio de Janeiro.

\footnotetext{
1 Inspirados nas perspectivas cotidianistas em Alves, N. (2008), adotaremos os usos das expressões das palavras compostas tais como 'ciberpesquisa', 'professorapesquisadora', dentre outras junções, com a finalidade de marcarmos os sentidos e a força política das palavras que buscam superar a dicotomização construída no período da ciência moderna. 2O termo "praticantes" possui a sua fundamentação nos referenciais teóricos de Certeau (2012). Ao se referir ao homem comum que se reapropria do cotidiano da vida numa sociedade de consumo através da utilização das táticas cotidianas. 3 Ciclo é um tempo sequencial de três anos, sem interrupções, no qual se consideram a alfabetização e o desenvolvimento de suas expressões, a partir da apropriação da leitura e da escrita.
} 
O mobile game Minecraft é um jogo digital, do gênero sandbox ${ }^{4}$, em que o jogador pode criar diferentes possibilidades para transformar o seu mundo virtual. É composto por um avatar - personagem que representa o jogador - blocos e ferramentas que possibilitam a criação de diferentes tipos de cenários. Pode ser jogado individualmente ou com outros jogadores, online (conectado a uma outra rede) ou offline (não conectado).

Nesse aspecto, deixando clara a relevância do papel da escola no contexto da sociedade contemporânea na valorização das diferenças e dos diálogos que compreenda o cotidiano como espaços formativos curriculares, esta pesquisa não teve a pretensão em argumentar sobre o mobile game Minecraft em uma perspectiva redentora. A ideia era demonstrar outras possibilidades de construção de conhecimentos, dentro do espaço escolar, e que nem sempre fazem parte do currículo oficial.

Dessa maneira, em busca de novos sentidos e significações, a investigação trouxe como questão norteadora a ideia em compreender como os usos do aplicativo mobile game Minecraft colaboraram para a criação de atos de currículos e experiências formativas na Educação Básica.

Sendo assim, fizemos uma abordagem multirreferencial com os cotidianos e com o método da ciberpesquisa-formação, através dos dispositivos: mobile game Minecraft e os diários de campo online (e - mails).

Os praticantes que chegavam à escola, campo investigativo desta pesquisa, nos traziam experiências fomentadoras de discussões, que, por sua vez, ampliavam os nossos sentidos, ao trazer conhecimentos significativos para todo o grupo. Os processos dialógicos e colaborativos emergiam através da realização de atividades que aconteciam em sala de aula e sinalizavam para a invenção de um currículo outro.

\section{Contextualizando a metodologia de pesquisa}

Os praticantes residiam nas proximidades da instituição, onde alguns, possuíam autonomia para os seus deslocamentos 'casaescola' e 'escolacasa'. Outros, necessitavam da presença do responsável para chegarem ou deixarem à unidade. São praticantes pertencentes a famílias de baixo poder aquisitivo, que no ano letivo de 2017, apresentavam

\footnotetext{
4 É um tipo de jogo em que são colocadas limitações mínimas para os personagens podendo modificar o mundo virtual de acordo com as preferências pessoais.
} 
modestos interesses pelos conteúdos pedagógicos. Quando solicitados para a realização das atividades, não demonstravam empenho ou mesmo algum tipo de satisfação pela realização delas. Entretanto, foi percebido que, do total de 20 praticantes, 17 alegavam conseguir acesso à internet, seja por meio dos seus respectivos smartphones ou daqueles pertencentes aos seus familiares, para além do espaço institucional.

Foi nesse contexto que a 'professorapesquisadora' e os praticantes, sujeitos desta pesquisa, iniciaram o ano letivo. A ideia de trabalhar com o mobile game Minecraft surgiu partir dos próprios interesses dos praticantes. Ao levarem o game para a sala de aula, apropriaram-se das astúcias em Certeau (2012) para reinventarem o cotidiano escolar — na tentativa de encontrarem novos sentidos e significados naquele espaçotempo. Alves (2008), buscando compreender o cotidiano escolar, nos traz a elucidação de que:

[...] as atividades dos cotidianos escolares ou dos cotidianos comuns, exige que esteja disposta a ver além daquilo que outros já viram e muito mais: que seja capaz de mergulhar inteiramente em uma determinada realidade buscando referências de sons, sendo capaz de engolir sentindo a variedade de gostos, caminhar tocando coisas e pessoas e me deixando tocar por elas, cheirando os odores que a realidade coloca a cada ponto do caminho diário (ALVES, 2008, p.19).

Ao perceber a admiração pelo game, a 'professorapesquisadora' solicitou ao grupo que a ensinasse um pouco mais sobre a jogabilidade. A partir desse momento, o mobile game Minecraft serviu como dispositivo inicial de pesquisa para que emergissem experiências outras que nos fizessem pensar sobre. Foram cerca de duas horas diárias, cinco dias por semana, totalizando aproximadamente 440 horas de navegação no referido game. Todavia, foi no curso de mestrado em educação que percebi na ciberpesquisaformação a exigência para o mergulho. Um mergulho nas narrativas a partir das experiências do mobile game Minecraft. Como 'professorapesquisadora', percebi que havia escolhido a alternativa do "[...] grande mergulho na realidade cotidiana da escola e nunca exercitando o tal olhar distante e neutro que me ensinaram e aprendi a usar" (ALVES, N. 2008, p. 20).

\section{Um acionar outro a partir da ciberpesquisa-formação}

Através da imersão de novos conhecimentos, privilegiamos como dispositivos o uso do mobile game Minecraft e dois diários de campo online (e-mails). Pensamos em 
dispositivos através das reflexões em Ardoino (2003, p.80), como "uma organização de meios materiais e/ou intelectuais, fazendo parte de uma estratégia de conhecimento de um objeto". Para tanto, esses dispositivos foram contextualizados através da ciberpesquisa formação, compreendida como estrutura investigativa metodológica que desse conta das questões em estudo.

Ao iniciar esta pesquisa, deparei-me com inúmeras escolhas. Uma delas relacionada ao procedimento metodológico que atendesse efetivamente às questões de estudo. Procedimento que, ao ser trilhado com um rigor outro, pudesse nos levar a alguns achados.

Macedo (2010) argumenta que esse "rigor outro" nos coloca na formação experienciada de uma epistemologia plural, crítica e emancipacionista, que, por sua vez, acaba por dialogar com a nossa prática. Os diários, potencializadores de novas experiências curriculares, nos proporcionaram reflexões outras sobre todas as possibilidades relacionais que estavam sendo tecidas entre a 'professorapesquisadora' e os praticantes.

O diário de campo online coletivo que os praticantes tinham acesso era composto por imagens inventadas dentro do mobile game Minecraft e algumas narrativas emersas do grupo. No diário de campo online pessoal havia dilemas, encantos e curiosidades que me faziam ressignificar as minhas práticas pedagógicas.

O dinamismo para a conclusão das atividades, a curiosidade para ver as invenções do outro e a marcação do tempo para a utilização dos smartphones, para que todos pudessem ter acesso à jogabilidade, apontavam para trilhas outras a serem experienciadas.

Barbosa (2004) fez uma afirmação interessante sobre a utilização do diário de pesquisa virtual com os seus praticantes, levando-nos a compreender essas experiências com o grupo como estratégias pedagógicas.

Dessa forma, o Diário de Pesquisa Virtual tornou-se, para todo o grupo, uma estratégia pedagógica formativa para o desenvolvimento dos conceitos e dos movimentos possíveis na utilização das tecnologias de informação e comunicação, possibilitando a todos o exercício de uma prática multirreferencial, entendendo a perspectiva multirreferencial como um olhar complexo que o pesquisador "empresta" às práticas educativas e, no caso, a possibilidade de instituição de um lugar para o outro (Barbosa, 2004, p.166).

É nessa perspectiva que o diário de campo online me fez perceber a existência, não apenas de um olhar único e rigorosamente fixo para uma dada realidade, mas diferentes possibilidades para diferentes interpretações, valorizando as narrativas e a construção dentro do game como experiências formativas em ato. Assim, tendo em vista a natureza 
do problema investigado, o diário de campo online, mais do que um espaço para os registros, possibilitava reflexões e nos oferecia compreensões maiores sobre as relações que estavam sendo tecidas.

Inicialmente, por decisões internas, a unidade escolar não permitia a utilização dos smartphones pelos praticantes. Todavia, posteriormente, através do diálogo, a instituição autorizou a realização do trabalho com o mobile game Minecraft a partir dos três dispositivos (smartphones) pessoais. Além disso, como a instituição não possuía rede de conexão WIFI, realizávamos as construções no game através do modo offline.

As dificuldades apresentadas em nenhum momento nos intimidaram. Ao contrário, forjaram em nós um sentimento de resistência e necessidade de cooperação. Sentíamos vontade de fazer pesquisa, experimentar o game, criar um outro currículo, e, isso, naquele momento nos instigava por novas descobertas.

\section{As invenções no mobile game no contexto das aulas}

As invenções no mobile game aconteciam em dois momentos, no primeiro, realizávamos uma discussão coletiva sobre os diferentes temas e questionamentos trazidos pelos praticantes. Esses temas faziam parte dos seus cotidianos, para além do espaço escolar tais como, as notícias retiradas da internet ou do próprio contexto em que habitavam.

A coletividade sugeria as temáticas que poderiam ser trabalhadas durante a semana e pesquisavam os temas com livros de histórias, revistas e jornais, trazidos pela 'professorapesquisadora', além do site de busca Google. Este último era acessado pelos praticantes fora da escola. Eles anotavam as suas observações e levavam para a sala de aula no dia seguinte para a realização das discussões coletivas.

Em um segundo momento, após o término das atividades cotidianas como as discussões e as construções coletivas realizadas sobre um dado tema, os praticantes jogavam até quinze minutos em offline. Além de brincarem com o jogo, a ideia era de que conseguissem construir no mundo virtual do mobile game Minecraft as suas compreensões sobre o que havia sido discutido anteriormente em sala de aula.

Em virtude dos horários de saída da escola, porém, com a flexibilidade das negociações no cotidiano escolar, algumas invenções precisavam ser concluídas no dia 
seguinte. Geralmente, quando esse fato acontecia, o tema do dia anterior se entrelaçava e se enriquecia com novos comentários.

Importa ressaltar que, com o passar do tempo, percebíamos que as temáticas eleitas pelo grupo se desdobravam em outras, o que, por sua vez, geravam outros tipos de discussões para além da que esperávamos. Por esse motivo, como 'professorapesquisadora' realizava os planos de aula simultaneamente e não mais como atividades pré-agendadas. Nesse contexto, os praticantes e a 'professorapesquisadora' inventavam projetos a partir das discussões coletivas. Eram atividades interligadas que expressavam as experiências formativas no grupo que juntas deram origem ao livro virtual Aventura Quadrada, composto pelas narrativas e criações de imagens dentro do game.

As "construções" no game, que ao cursar o mestrado em educação compreendi como "invenções", de acordo com Certeau (2012), criadas no mobile game Minecraft pelos praticantes dessa pesquisa, eram enviadas para dois diários de campo online (e-mails). Um dos diários de campo era de uso coletivo, onde todos poderiam participar. A senha era coletiva e cada praticante assumia o compromisso de mantê-la para não prejudicar o acesso dos demais colegas. É importante pontuar que, durante a realização deste projeto, esse acordo não foi quebrado, o que pode ser interpretado como o fortalecimento das interações sociais que estavam sendo tecidas. O outro diário de campo online era o e-mail de uso pessoal. Nele, eram colocados os dilemas da 'professorapesquisadora' (acontecimentos que emergiam durante as aulas) e encantamentos sobre as experiências formativas que estavam acontecendo. Zabalza (1994, p.19) argumenta que o dilema é "todo o conjunto de situações bipolares ou multipolares que se apresentam ao professor no desenrolar da sua atividade profissional". Esses registros, por outro lado, favoreciam experiências, pois, nos possibilitava investigar e refletir sobre as práticas, criando com isso, possibilidades outras de intervenção.

É importante destacar também que, mesmo que o APP do mobile game Minecraft seja um game comercial, concordo com Jenkins (2004, apud ARRUDA, 2009), quando ele afirma que os jogos comerciais, ainda que não sejam produzidos e direcionados para o ensino, proporcionam espaços de aprendizagens, que são mais "abertos" e possibilitam ao jogador maior liberdade de ação.

Em contrapartida, Santaella (2004) considera que as mídias digitais, nas quais se insere o game, caracterizam-se por um complexo processo de integração entre 
conhecimento científico e senso comum, o que impossibilita identificarmos o seu início ou seu término. Logo, uma das principais características das mídias digitais seria minimizar as fronteiras dos saberes, sem, no entanto, trazer prejuízos ao conhecimento científico.

Certamente, as novas tecnologias trouxeram uma descentralização territorial das aprendizagens. Através dos dispositivos móveis, os praticantes passaram a ter acesso às informações que geralmente a instituição investigada não oferecia, como o ingresso do game Minecraft no cotidiano escolar. Então, aquele sujeito nativo de Prensky (2012) tem em sua cultura novas nuances que precisam ser levadas em conta pela instituição. É nesse contexto que o aplicativo do Minecraft desperta nos praticantes possibilidades e interesses que podem ser significativos para o processo de construção de um currículo escolar mais flexível, construído e tecido pelos praticantes no contexto da orientação coletiva pela 'professorapesquisadora'.

Certeau (2012, p. 15) nos conta que "os dados estatísticos não evidenciam a bricolagem, a inventividade artesanal, a discursividade que combinam esses elementos". Por isso, é importante enfatizar que a pesquisa de campo não procurou coletar dados. Mas, como bem nos lembra Santos, E. (2014), na 'pesquisaformação' os dados não são coletados; são produzidos em atos. Atos e experiências registrados através do diário de campo online com vídeos, fotos e prints das cenas inventadas pelos praticantes dentro do mobile game Minecraft.

Diante do exposto, a abordagem teórico metodológica adotada para investigar a utilização do aplicativo do mobile game Minecraft cooperou para a aproximação entre a 'professorapesquisadora' e os praticantes, pois, por meio dos constantes diálogos que foram sendo tecidos ao longo do processo investigativo, podemos perceber as inferências significativas presentes nas falas, nas atitudes e principalmente nas diferentes leituras resultantes desse movimento.

\section{Resultados}

A transformação em ressignificar a prática formativa, nos remete a Macedo (2010), em relação às perspectivas dos atos do currículo. A participação colaborativa promovida a partir da utilização do mobile game Minecraft, explorando diferentes possibilidades criativas a partir das invenções realizadas dentro do game, faziam emergir as invenções. 
Cada invenção desenvolvida pelos praticantes, nos revelava o pensamento multirreferencial de Ardoino (1998), ao nos sugerir que todos precisam ser ouvidos, todos precisam ser olhados pluralmente. $O$ estudo desse autor deixa claro que, quanto maior for a apropriação dos praticantes como protagonistas de suas reflexões e sensibilidades a partir das experiências, mais encontrarão outros sentidos e significados para essas mesmas experiências, o que possibilita a criação de novos conhecimentos para as suas vidas. Mas, como se daria a relação desses praticantes com a experiência com o mobile game Minecraft?

Reiteramos que os praticantes da contemporaneidade, conectados, possuem diferentes tipos de possibilidades para a construção de novas interações sociais para agregarem conhecimentos. É possível dizer, portanto, que estamos diante de um cenário emergente, em que a escola, locus do saber, precisa dialogar com os artefatos tecnológicos como potencialidades.

A aprendizagem mediada pelas tecnologias ainda é na atualidade um desafio, tanto para o professor quanto para o praticante, pois não leva em conta somente a habilidade técnica no uso das máquinas, mas, contempla toda a inserção desse equipamento nas práticas voltadas para a aprendizagem e, consequentemente, uma multiplicidade de linguagens, culturas, sentidos e significados.

Diante disso, fez-se necessário compreender as potencialidades dos aplicativos dos jogos digitais, como o mobile game Minecraft, para melhor aproveitá-lo no decorrer das práticas pedagógicas. Como forma de diálogo e abertura de possibilidades para a construção de um outro currículo possível, cuja existência possua significados para além da grade, nos trazendo significados e ressignificações em autorias através de experiências formativas.

O conceito de autoria pode ser compreendido por Amaral (2014, p.72) como "toda criação intelectual, expressão do pensamento, que se manifesta na obra, seja por meio de um texto escrito (palavra), imagens e formas, escrita cênica, performance, entre outros, a partir da realidade sócio-histórica em que nos inserimos". Desse modo, construído dentro do processador de texto Microsoft Word5, a partir das invenções e das narrativas dos praticantes, o livro Aventura Quadrada foi uma organização da 'professorapesquisadora' e

5 Software da Microsoft Office. 
dos praticantes como registro incentivador que apresentasse as potencialidades do grupo. Os projetos e as autorias se interligavam e, à medida que os praticantes se autorizavam, novos projetos emergiam. Nos impressionava os constantes esforços do grupo em estudar e apreender os conteúdos discutidos para que conseguíssemos inseri-los no game através das invenções. Ainda que, nas segundas-feiras realizássemos um levantamento sobre os possíveis temas que seriam trabalhados, durante os outros dias da semana, surgiam desdobramentos outros que nos colocavam diante de novos conhecimentos.

As narrativas com o grupo nos apontavam sobre a possibilidade de diferentes caminhos. Um deles, era a invenção do projeto "A preservação da natureza depende de quem?" Esse projeto surgiu a partir das narrativas de um dos praticantes ao nos contar sobre a sua relação com a natureza. A criança possuía o hábito de tomar banho no rio e caçar garças para ajudar no fornecimento de suprimentos alimentares em sua casa. A curiosidade sobre essa história fez com que o grupo pensasse sobre a preservação da diversidade ambiental. No entanto, os praticantes decidiram inovar e acrescentaram um dos heróis da Marvel Comics - editora de quadrinhos americanos, fundada nos Estados Unidos em 1959 - Homem de Ferro, para demonstrarem um possível protetor da natureza.

\section{I - Invenção do Homem de Ferro - Praticante Madson (10 anos de idade)}

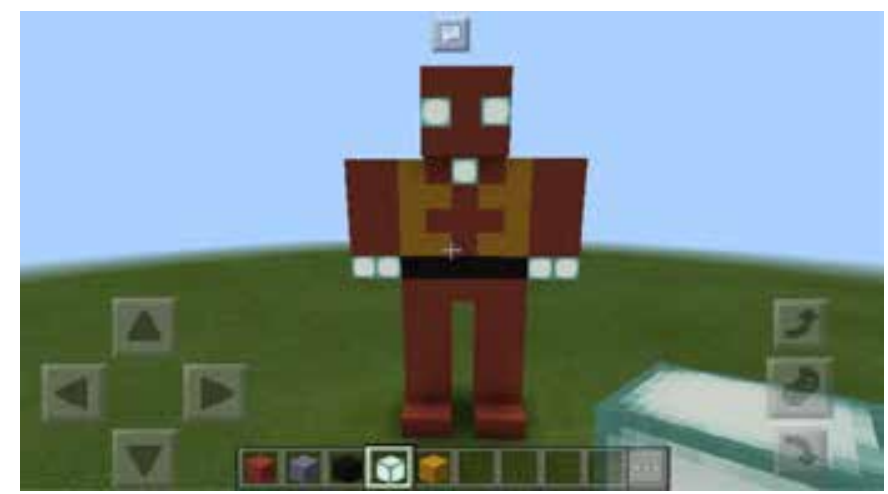

Fonte: Arquivo pessoal.

Praticante Madson (10 anos de idade): - O homem de ferro vai proteger a natureza. Se vier alguém tentando colocar fogo na natureza, ele usará os seus poderes.

2 - Invenção das queimadas na floresta - Praticante Fabrício (11 anos de idade) 


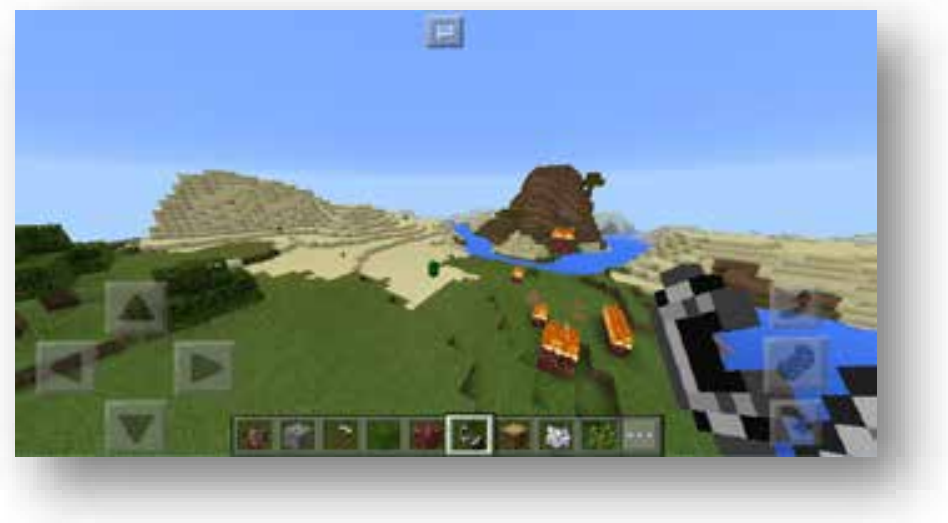

Fonte: Arquivo pessoal.

As formas inventadas de ser dos praticantes também reiventavam a professorapesquisadora. As crianças narradoras puxavam para si a centralidade do processo. Os seus sonhos, as suas fantasias passaram a fazer parte do currículo escolar. As invenções traziam um colorido entre os blocos do game que nos faziam sonhar e acreditar em uma outra escola possível. As invenções surgiam como fontes inspiradoras e repletas de conselhos que nos faziam transitar entre as narrativas experienciadas. Recorro a Macedo (2015), quando nos propõe não transformarmos a experiência em uma interpretação reduzida, uma vez que a experiência humana é irredutível e mediada por referências múltiplas. Nessa lógica, não deveríamos realizar comparações e, sim, perpectivas constrativas.

Os saberes da experiência resultam do vivido pensado. Acrescenta-se, que a compreensão da experiência só se fará por atos de compartilhamento de sentidos e significados. Tendo como fonte fulcral a vivência singular dos sujeitos na sua emergência existencial e sociocultural, a experiência se estrutura como um denso e complexo processo de subjetivação de tudo que nos acontece, que nos passa, mediado por desejos, escolhas e intenções conscientes ou não, lúcidas ou erráticas, plasmados num certo tempo mas, também, tocada intensamente pela impermanência. Se expressando, a experiência produz, invariavelmente, o estranhamento porque dá corpo e potência à diferença em ato e sua capaciadede de produzir alteridade e de forma mais impactante e significativa, a criação de alterações, mediante a presença do outro e sua inerante capacidade em nos deslocar. (MACEDO, 2015, p.19)

As experiências defendidas por Macedo (2015) nos sugerem reflexões e ressignificaçãoes que se iniciam a partir da consciência da autoria. A experiência com o mobile game Minecraft possibilitou que as autorizações acontecessem no grupo. A professorapesquisadora autorizou-se a realizar os projetos que surgiam em sala de aula e ressignificá-los através de diferentes possibilidades interpretativas. Os praticantes, por sua 
vez, se autorizavam na medida em que mergulhavam no ambiente imersivo (Santaella, 2003), tecnológico, trazendo outros sentidos, leituras e significados para além do game. Nos fazendo descobrir que " A experiência não se verifica, se compreende.” (MACEDO, 2015, p.19)

Ao longo dos dias, durante a realização do projeto $A$ preservação da natureza depende de quem?, percebíamos o quanto precisávamos compreender um pouco mais sobre os diferentes aspectos da natureza relacionando as suas formas de vida. Foi nesse instante, que o praticante Matheus William (09 anos) nos surpreendeu ao construir no Minecraft os animais vertebrados e invertebrados.

Praticante Matheus William (09 anos de idade): - Tia, eu ontem saí da escola e fiquei pensando ... Os animais invertebrados são molengas como as minhocas. Todas as vezes que vou no meu quintal e brinco com a terra preta, elas estão lá. Grandes, pequenas, gordas, magras. Elas fazem túneis para se esconderem e dar oxigênio para a planta. Então, fiz aqui no jogo o mundo das minhocas (risos)

A narrativa de Matheus William fomentava a curiosidade para a experiência. A terminalidade da aula não o impedia de continuar em seus processos formativos. A criança usou os conhecimentos trabalhados no cotidiano escolar no seu dia a dia. A descoberta fazia parte do cenário e as suas posteriores invenções no game mostravam as suas compreensões sobre a temática. O praticante construiu as minhocas virtuais, coloridas e enfileiradas como uma representação simbólica do vivido. Convido Santos, E. e Weber (2018, p.24) para pensarmos sobre os ambientes virtuais de aprendizagens.

\footnotetext{
Primeiramente, precisamos instituir a sala de aula ou campo de pesquisa online. A partir do uso de ambientes virtuais de aprendizagem, que são um híbrido de objetos técnicos e seres humanos em processo de comunicação em rede, podemos desenvolver conteúdos, situações de aprendizagem e dispositivos de pesquisa que lancem mão de diversas interfaces, ou seja, de canais de comunicação entre os sujeitos e os conhecimentos por eles produzidos, compartilhados e negociados no ambiente virtual de aprendizagem. Cada interface é em si uma mídia, que não só produz como veicula as mensagens e narrativas e, consequentemente, o processo de comunicação e de aprendizagem. Assim, produzimos e negociamos sentidos, educamos e nos educamos, formamos e nos formamos, pesquisamos e somos pesquisados. (SANTOS, E. e WEBER, 2018, p.24)
}

Nesse sentido, percebemos que a produção e a negociação de sentidos fizeram parte dos processos de subjetividades inerentes aos novos conhecimentos. A sede pela descoberta nos inquietava cada vez mais. Talvez, o que Matheus William não imaginasse 
era que a possibilidade da invenção dos animais invertebrados no Minecraft despertasse nos praticantes a vontade de inventarem conhecimentos através de projetos outros.

O desenvolvimento deste estudo, marca o início do diálogo com os pressupostos da pesquisa com os cotidianos, apoiados nos dispositivos mobile game Minecraft e o diário de campo online no campo investigativo, como estímulo à criatividade, bem como as relações sociais entre jogadores por meio de processos interativos, dialógicos e colaborativos.

\section{CONSIDERAÇÕES FINAIS}

A abordagem teórico metodológica adotada para investigar a utilização do aplicativo do mobile game Minecraft possibilitou a aproximação entre a 'professorapesquisadora' e os praticantes. Através dos constantes diálogos que foram sendo tecidos ao longo do processo investigativo em análise, puderam ser percebidas as inferências significativas que estavam presentes nas narrativas, nas atitudes e, principalmente, nas diferentes leituras e interpretações a partir das experiências formativas.

Ter tecido a ciberpesquisa formação, agregando as experiências, a partir do objeto em estudo com os praticantes desta pesquisa, criou a permissão necessária para o rompimento com a resistência pessoal diante das tecnologias digitais. Por outro lado, não houve a pretensão de pensarmos a cibercultura como uma perspectiva redentora.

Desse modo, no presente campo investigativo, a possibilidade de refletirmos com uma lógica outra, para além das fragmentações conteudistas, tão visíveis na grade curricular, percebíamos os praticantes em suas pluralidades, atribuindo diferentes sentidos às suas diversificações e criatividades, cooperando para que eles pudessem se reinventarem.

Nesse aspecto, apreendemos que as aprendizagens mediadas pelas tecnologias digitais nesta pesquisa, se tornaram desafiadoras tanto para a 'professorapesquisadora' quanto para os praticantes. Esse fato decorre do entendimento de que não foram levados em conta somente as habilidades técnicas nos usos do mobile game Minecraft, mas as inserções desses equipamentos nas práticas pedagógicas voltadas para as aprendizagens, nos revelando, consequentemente, uma multiplicidade de linguagens, culturas, sentidos e significados. 
Assim sendo, inferimos que as aprendizagens decorrentes das experiências nas relações interativas e colaborativas nos levaram à compreensão da perspectiva da 'ciberpesquisa' formação. Os conhecimentos relacionados aos diferentes sentidos e significados trazidos pelos usos com o game Minecraft possibilitavam atos de currículos que valorizassem as experiências como possibilidades formativas.

\section{REFERÊNCIAS}

ALVES, N. Sobre movimentos das pesquisas nos/dos/com os cotidianos. In: OLIVEIRA, I. B. de; ALVES, N. (org.). Pesquisa nos/dos/com os cotidianos das escolas: sobre redes de saberes. 3. ed. Petrópolis: DP \& A, 2008.p.24-34.

AMARAL, M.M. Autorias docente e discente: pilares de sustentabilidade na produção textual e imagética em redes educativas presenciais e online. 2014. Dissertação (Mestrado em Educação) - Programa de Pós-graduação em Educação, Universidade do Estado do Rio de Janeiro, Rio de Janeiro, 2014.

ARDOINO, J. Para uma Pedagogia Socialista. Brasília. Editora Plano, 2003.

ARDOINO, J. A formação do educador e a perspectiva multirreferencial. Revista Quadrimestral da Associação Brasileira de Psicologia Escolar e Educacional, São Paulo. v.18, n. 3, Set./Dez. 2014. P. 467-476. Disponível em:

http://www.scielo.br/scielo.php?script=sci_nlinks\&ref=000141\&pid=S14132478200400020 000700005\&lng=en. Acesso em: 24 out 2018.

ARRUDA, E. P. Jogos digitais e aprendizagens: o jogo Age of Empires III desenvolve ideias e raciocínios históricos de jovens jogadores? 2009. Tese (Doutorado em Educação) - Programa de Pós-graduação em Educação, UFMG, Belo Horizonte,2009. Disponível em : file:///C:/Users/lilie/Desktop/COISAS\%20DO\%20PROJETO/TESES\%20E\%20DIS.\%20MAIS\%20US ADAS/TESE\%20EUCÍDIO.pdf. Acesso em: 01 set 2020.

BARBOSA, J. G. O pensamento plural e a instituição do outro. Educação e Linguagem, São Bernardo do Campo, v. 7, n. 9, jan./jun. 2004. p. 11-122.

CERTEAU, M. A invenção do cotidiano: artes de fazer. 19. ed. Tradução de Ephraim Ferreira Alves. Petrópolis: Vozes, 2012.

MACEDO, R.S. Compreender e mediar a formação: o fundante da educação. Brasília: Liber Livro, 2010.

MACEDO, R.S. Pesquisar a experiência compreender/mediar saberes experienciais. 1.ed. Curitiba: CRV, 2015. 
MATURANA, L.L. R. Mobile game na educação básica: experiências docentes e discentes de ciberpesquisa formação multirreferencial. Dissertação (Mestrado em Educação). Programa de Pós-graduação em Educação, Universidade do Estado do Rio de Janeiro, Rio de Janeiro, 2020.

SANTAELLA, L. Culturas e artes do pós-humano: da cultura das mídias à cibercultura. São Paulo: Paulus, 2003.

SANTAELLA, L. Navegar no ciberespaço: o perfil cognitivo do leitor imersivo. São Paulo: Paulus, 2004.

SANTOS, E.; WEBER, A. Pesquisa formação na cibercultura. 1. ed. Santo Tirso: Whitebooks, 2014.

SANTOS, E.; WEBER, A. Diários online, cibercultura e pesquisaformação multirreferencial. In: SANTOS, E.; CAPUTO, E.G. Diário de pesquisa na cibercultura: Narrativas multirreferenciais com os cotidianos. Rio de janeiro: Ômodê, 2018.

ZABALZA, M. A. Diários de aula: um instrumento de pesquisa e desenvolvimento profissional. Trad. Ernani Rosa. Porto Alegre: Artmed, 1994.

Recebido em: 05/05/2020

Parecer em: $18 / 12 / 2020$

Aprovado em: 10/01/2020 